\title{
ARTículos AcAdémicos
}

\section{Desafíos del derecho de la protección de datos en días de globalización}

\section{Challenges of the right of data protection in days of globalization}

\author{
Suly Peralta Orosco ${ }^{\prime}$ \\ Universidad Nacional Mayor de San Marcos \\ speraltaorosco@gmail.com
}

Presentado: 16/03/2019 - Aceptado: 25/09/2019 - Publicación: 12/04/2021

\begin{abstract}
Resumen
Los Derechos Humanos contienen, en sí mismos, sustratos esenciales dinámicos por naturaleza que requieren ser protegidos atendiendo a los nuevos escenarios en que se actualmente se proyectan. La sociedad informatizada orientada por el uso de las Tecnologías de la Información y Comunicación cuanto más evoluciona, invade con mayor fuerza la esfera de derechos y libertades, en sus diversas manifestaciones. El derecho a la intimidad es, probablemente, uno de los más afectados, exige por ello su permanente revisión a la luz de la ciencia jurídica.
\end{abstract}

Palabras clave: Desafío; protección de datos; globalización; tecnologías.

\begin{abstract}
Human Rights contain, in themselves, essential dynamic substrates by nature that need to be protected taking into account the new scenarios in which they are currently being projected. The computerized society, guided by the use of Information and Communication Technologies, the more it evolves, the more forcefully it invades the sphere of rights and freedoms, in its various manifestations. The right to privacy is probably one of the most affected, and therefore requires its permanent revision in the light of legal science.
\end{abstract}

Keywords: Challenge; data protection; globalization; technologies.

(c) Los autores. Este artículo es publicado por Lucerna luris Et Investigatio de la Facultad de Derecho y Ciencia Política de la Universidad Nacional Mayor de San Marcos. Este es un artículo de acceso abierto, distribuido bajo los términos de la licencia Creative Commons Atribución 4.0 Internacional (CC BY 4.0) [https://creativecommons.org/licenses/by/4.0/deed.es] que permite el uso, distribución y reproducción en cualquier medio, siempre que la obra original sea debidamente citada de su fuente original. 


\section{Introducción}

Como consecuencia de una sociedad sometida a cambios constantes - desde que la primera civilización se asentara en la antigua Mesopotamia hasta el reciente fomento de un orden social en pacífica convivencia (por lo menos en apariencia) propiciada a través de distintos Organismos Internacionales - la misma ha ido logrando un mayor desarrollo de manera vertiginosa a lo largo de los años, llegando en ocasiones a traspasar el escenario imaginario de una película de ciencia ficción.

En esa dirección, a lo largo de las últimas décadas y con mayor intensidad en lo que va de ésta última se ha podido notar que el radio de proyección en que las Tecnologías de la Información y Comunicación (TICs) han ido desplegándose ha sido cada vez mayor, en todos los sentidos, esto es, tanto a nivel de espacio como a nivel de espacios, ello innegablemente también debido, en gran medida, a la importancia que su uso representa para el desarrollo de la economía global que a menudo requiriere reducir la velocidad de sus procesos.

Convulsionando así a la comunidad mundial con una serie de vías, herramientas, formas, redes y mecanismos convenientes en la comunicación y tráfico de la información en tiempo real, pero con ello también de una mayor exposición de diferentes aspectos de la vida en considerables dimensiones, y consecuentemente con mayores posibilidades de amenaza y vulneración a una serie de derechos y libertades universales inherentes al ser humano.

Frente a un horizonte como éste, los diversos países e incluso organismos internacionales han ido adoptando diversas medidas en el intento de frenar los efectos colaterales de la casi lograda Sociedad Globalizada concretizada en esa dimensión llamada realidad virtual - donde no existen distancias, fronteras, diferencias horarias ni idiomáticas - por cuanto su evolución ha traído consigo una serie de problemas que conciernen directamente a la ciencia jurídica en su fin último de proteger a la persona y su dignidad en tanto núcleo irreductible de su existencia.

Sociedad informatizada que al haber redimensionado la esfera de desarrollo de la persona, de su ámbito real al infinito espacio virtual de contenidos y servicios a su disposición, ha dado lugar a un aspecto nuevo, pero que no por ello le deja de ser propio e inalienable, como es el de su personalidad virtual, generando así la inminente exigencia de establecer nuevos mecanismos de protección al ser humano, tanto en su persona y personalidad físicas como de su neo atributo inescindible de personalidad virtual.

Ello debido en gran medida a que, en la actualidad resulta poco más que complicado pretender no subirse a dicha plataforma, ya que hacerlo se ha convertido esencial, tanto para el desarrollo mismo de la persona en su espacio 
tangible, ya sea para satisfacer sus variadas necesidades, de: administración financiera, consumo de bienes y servicios, acceso educativo, inserción en el mercado aboral, atención médica, relaciones sociales, espacios comerciales, intereses académicos y un abanico más de posibilidades que de algún modo lo constriñen a actuar y ser parte de ese nuevo escenario, como para atender las necesidades de un Estado de: mejorar sus sistemas de organización y seguridad, tecnificar sus políticas económicas y de criminalidad, y demás, para lo que tienden a registrar datos de sus ciudadanos, sin que estos tengan elección.

Proyección que como ya se ha advertido - debido a la gran cantidad de redes y flujos de información a la que cotidianamente pueden conectarse millones de personas, con la misma cantidad de múltiples intereses cada uno, y muchos de ellos incluso con identidades que desaparecen rápidamente sin dejar rastros - ha ido invadiendo cada vez con mayor fuerza la esfera de derechos y libertades del hombre, en sus diversas manifestaciones, tales como, el de intimidad, del secreto de las comunicaciones, a la imagen, al honor, a la seguridad e integridad física, y el de interdicción de discriminación, solo por citar algunos de ellos.

De modo que, al haberse difuminado los límites entre el ámbito público, el ámbito privado y el ámbito íntimo, así como entre el desarrollo offline y el desarrollo online de la personalidad, como consecuencia de introducirse en esta nueva esfera, sin que para ello haya habido ocasión de observar previamente normas establecidas, es que resulta ahora, ya no solo necesario sino sumamente necesario y urgente estudiar y redefinir algunas categorías de derechos humanos ya existentes para, a partir de ello, separar algunos aspectos y reconocer nuevos derechos emergentes que conlleven a la producción de una adecuada regulación que pueda ser aplicada a la nueva realidad de la Sociedad Informatizada.

\section{Gestación: Del Derecho a la Privacidad al Derecho a la Intimidad}

Los Derechos Humanos contienen en sí mismos sustratos esenciales cambiantes que el ser humano necesita le sean protegidos, conforme pasa el tiempo y la sociedad evoluciona, y muestra de ello se puede ver en como con el paso del tiempo se han ido reconociendo diferentes derechos, atendiendo a un momento histórico diferente cada uno, tal es así que doctrinariamente no es extraño clasificar a los derechos en generacionales, y lo propio ocurre con el contenido de cada uno de los derechos y libertades, dinámicos por su propia naturaleza, atendiendo siempre a los nuevos escenarios en que se deben proyectar.

En ese sentido, subsecuentemente se intentará desarrollar los nuevos contenidos gestados por el Derecho a la Intimidad y delimitarlos del contenido del Derecho a la Extimidad ${ }^{2}$, no obstante, antes de llegar a ese 
punto, resulta menester repasar sus antecedentes y su evolución para un mejor entendimiento de sus alcances. Así, se inicia dicho repaso con el clásico "the right to be let alone" entendido como el derecho a ser dejado solo o a no ser molestado - en tanto hito de suma importancia para el posterior desarrollo del derecho que motiva la presente, el de intimidad - concepto que fuera introducido el año 1879 por el juez Thomas M. Cooley con la primera edición de su "Treatise on the Law of Torts", en la que afirmaría: “... el derecho de la persona a protegerse frente a invasiones de la privacidad alcanza tanto frente a la intromisión ilegal de los agentes del gobierno como frente a la curiosidad lasciva del público en general." (Saldaña, 2012, p. 206) planteamiento que fuera acogido más tarde en 1886, por el Tribunal Supremo de los Estados Unidos en el caso Boyd vs. United States.

Concepción que evoluciona luego como respuesta a la creciente preocupación de la aún incipiente sociedad tecnológica emergente de fines del siglo XIX surgida por la actuación invasiva a la privacidad de una prensa sensacionalista que veía a la persona como objeto mercantilista de distracción publica, robustecida gracias a los avances tecnológicos de ese momento; como en efecto se lo habría hecho saber el abogado Samuel D. Warren (enojado por continuos abusos a su privacidad) a su socio de un bufete en Boston, el también abogado Louis D. Brandeis sugiriendo una redacción sobre el particular (Arce, 1996, p. 368), concretado en su artículo intitulado "The Right to Privacy" de la edición $\mathrm{N}^{\circ} 05$ de la Harvard Law Review, publicado en fecha 15 de diciembre de 1890, que daría lugar al nuevo concepto de "the right to privacy" entendido como el derecho a la privacidad (que comprende el desarrollo de diferentes libertades de la persona). Momento a partir del cual se abriría una inacabable discusión con avances y retrocesos en la doctrina y jurisprudencia americana, pasando así a desarrollar más tarde el Tribunal Supremo de los Estados Unidos conceptos como (Saldaña, 2011, p. 279-312): "fundamental right to privacy", el "test de expectativa razonable de privacidad" o el de "constitutional right to informational privacy", sobre los que por ahora no es nuestra intención abundar.

Derecho a la Privacidad del sistema americano que lógicamente tuvo lugar a repercusiones en el denominado sistema continental y también luego en el hibrido sistema iberoamericano, desarrollado, sin embargo, bajo la forma de Derecho a la Intimidad, precisando que la diferencia no se circunscribe únicamente al aspecto lingüístico de su nomenclatura, sino que en realidad ambos versan sobre diferenciados espacios de protección de la expresión del Derecho de Libertad, abarcando el Derecho a la Intimidad la protección de una esfera más reducida en relación a las facetas más reservadas de la vida del hombre.

Así, en relación a la intimidad, resulta oportuno reproducir las palabras apuntadas por Eduardo López Azpitarte (1990), quien 
con acertada precisión señalara: “Todo ser humano guarda siempre un misterio en su corazón, una zona reservada a la mirada indiscreta de cualquier otro, que constituye el núcleo más hondo y arraigado de su personalidad, aquello que le hace sentirse autónomo y diferente. Se trata de todo ese mundo interior donde anidan y se esconden los sentimientos, deseos, ilusiones, pensamientos, alegrías y penas, nostalgias o vergüenzas, experiencias e historias, acontecimientos $y$ omisiones ..., que son nuestro patrimonio más auténtico, lo único que nos pertenece por completo, porque nos hace sentirnos como sujetos personales, no como un objeto cualquiera expuesto a la contemplación curiosa de los demás."(Delpiazzo, 2002, p. 253).

Prefacio que invita a recordar que, si bien a nivel puramente filosófico, desde períodos muy tempranos se tuvo conciencia y empezó a desarrollar el hecho de que, pese a concebir al ser humano como ente social por naturaleza a su propia existencia (atendiendo a sus instintos de supervivencia, conservación y preservación), no por ello se dejó de identificar en el mismo su necesidad de conservar para sí una vida plena ajena sus relaciones con otros individuos. Entendimiento que, sin embargo, no fue desarrollado simultánea y uniformemente a nivel jurídico, puesto que en este ámbito llevó mucho más tiempo llegar a ello - tanto en el derecho americano, como en el derecho europeo - siendo, en éste último, introducido explícitamente y con la categoría de un derecho fundamental recién en el año 1919 con la primera Constitución de la República Independiente de Finlandia que en su artículo 8 enunciaba la garantía del Derecho a la Intimidad, al Honor, a la Inviolabilidad de Domicilio y al Secreto de las Comunicaciones; precisando, sin embargo, que no sería sino hasta 1976 tras la dación de la Constitución de Portugal que se iniciaría un primer periodo activo de constitucionalización de este derecho, influenciado en parte por el hecho que éste habría sido el primer instrumento jurídico interno que desarrolló con mayor detalle dicho derecho, y en parte también por el momento histórico que atrás se dejaba e iba cerrando con la suscripción de instrumentos jurídicos internacionales como la Declaración Universal de Derechos Humanos de 1948 (artículo 12), el Convenio Europeo para la Protección de los Derechos Humanos y de las Libertades Fundamentales de 1950 (artículo 8), el Pacto Internacional de Derechos Civiles y Políticos de 1966 (artículo 17) y la Convención Americana sobre Derechos Humanos de 1969 (artículo 11).

En tal sentido, es posible afirmar que el desarrollo de este derecho, pese a ser relativamente moderno, en cuanto a su reconocimiento, ha sido muy progresivo en cuanto a su contenido y protección, así notamos que la proyección que inicialmente se le daba al contenido de este derecho - si bien en un ámbito más reducido que en el derecho anglosajón - era aún una concepción mucho más amplia, en cuanto al ámbito garantista a su intromisión, del que se le pretende dar en estos días. 
Para entender ello es preciso señalar que por Derecho a la Privacidad (Saldaña, 2012, págs. 195-240) se entiende: al derecho a la protección de aquellos ámbitos de la esfera privada que tienden a preservar los intereses a ser dejado solo (soledad), a vivir la vida que uno elige (individualidad), a mantener en reserva la vida privada (intimidad), a un desarrollo personal libre de agresión, intromisión o invasión (desarrollo de la personalidad), a la libertad de elección en asuntos personales (autonomía), al libre control de la información personal (autodeterminación), frente a las injerencias no deseables del Estado o de particulares, salvo justificadas excepciones.

Mientras que, por Derecho de la Intimidad se entiende al derecho que busca proteger, de la injerencia y divulgación por terceros, los aspectos más reservados de la vida de la persona que desea conservar para sí, en su ámbito personalísimo, talantes como el origen racial, étnico, ideologías políticas y culturales, convicciones religiosas, filosóficas o morales, afiliaciones partidistas o sindicales, cuestiones de salud, desarrollo sexual, situación financiera, riesgo crediticio, medidas de seguridad personal y familiar, y demás rasgos de su individualidad desarrollados dentro de los confines de lo que decida establecer como su vida privada, cuya vulneración pudiese llevar a afectar su imagen, nivel aceptación y seguridad.

Nótese entonces la marcada diferencia que ya inicialmente existía en cuanto a dichos atributos humanos, pues mientras el ejercicio y protección del Derecho a la Privacidad se despliega en tanto expresión misma del Derecho a la Libertad, en muchas de sus dimensiones, el ámbito del Derecho de la Intimidad, por su lado, únicamente se circunscribe en cuanto expresión del Derecho al Libre Desarrollo de la Personalidad, y es precisamente a partir de ello que el mismo ha ido sintiendo la necesidad de evolucionar en el sistema continental.

\section{Dimensiones del Derecho de la Intimidad:}

Este atributo, dinámico por su naturaleza propia como derecho humano, obedece en cierto modo a su necesidad de adaptarse a nuevos escenarios producidos por el paso del tiempo, es por ello que - de no haberse replanteado los alcances de su concepción - habría quedado reducido y vaciado en su contenido, tal es así que habiéndosele otorgado inicialmente una dimensión negativa (garantista en puridad), ahora es posible también reconocerle una dimensión positiva (titularidad activa del derecho), como se verá.

\subsection{Dimensión Negativa: Derecho a la Protección de Datos Personales}

También entendido como el Derecho $a$ la Intimidad en estricto, en el sentido de "la suma de principios, derechos y garantías establecidos en favor de las personas que pudieran verse perjudicadas por el tratamiento de los datos de carácter personal a ella referidos" (Puccinelli, 2004, p. 475), tendientes 
por ello a preservar la esfera delimitada por su vida privada para el libre desarrollo de la personalidad. Noción a partir del cual se extrae es - más que el reconocimiento de un derecho - el de una garantía a la persona en tanto núcleo irreductible de su atributo de Dignidad Humana, ya que, más que dotar de atribuciones a la persona en sí misma, traslada la mayor responsabilidad de la defensa y protección del mismo al ámbito del Estado, y por ello (como efecto colateral) impone a terceros la prohibición u obligación de abstenerse de ingresar indebida e ilegítimamente en dicha esfera.

Razón por la cual el Estado, antes que otorgarle al individuo instrumentos para la protección previa a la violación de su derecho, lo que hace es dotar de mecanismos de resarcimiento frente a una eventual vulneración o inminente amenaza, pudiendo el afectado en uno u otro caso, atendiendo a las circunstancias particulares del evento dañoso, ejercitar acciones constitucionales (vía un proceso de amparo), civiles (pretensión indemnizatoria) y/o penales (delitos contra el honor).

\subsection{Dimensión Positiva: Derecho de la Protección de Datos Personales}

Si bien es notable que inicialmente se concibiera a este derecho como una garantía en puridad, también es evidente que dicha noción no podría ser sostenible en el tiempo, ya que los muchos avances tecnológicos traen como resultado que el hombre esté, por uno u otro motivo, cada vez más expuesto y en muchas ocasiones debido a su propia liberalidad. En ese sentido resulta propicio, en el contexto actual, concebir como contenido esencial del derecho de la intimidad - en su dimensión positiva - al derecho de la protección de datos personales, el mismo que puede ser entendido como aquel derecho inherente al hombre moderno de contar con una regulación adecuada en la que se le reconozcan facultades, instrumentos de prevención y mecanismos de reivindicación suficientes para que pueda rechazar intromisiones ilegítimas en su esfera íntima, personal y familiar, en el ejercicio de su derecho conexo a la libertad, con cuya garantía, seguridad y tranquilidad pueda consiguientemente ejercer un mayor control y dominio de la información que le concierne y determinar libremente su nivel de permisividad sobre la misma, sin que ello implique necesariamente que se trate de información sensible en estricto.

De lo que se logra advertir una marcada diferencia con el contenido esencial del antes comentado derecho a la protección de datos personales, pues en este último, si bien todavía se exige una notable y hasta mayor presencia del Estado e impone las mismas medidas de prohibición implícitas a terceros, se opta además por dotar al sujeto de los medios necesarios para la defensa de su derecho (Habeas Data y, en teoría, medidas administrativas y judiciales), reconociéndosele por ello una intervención mucho más libre y activa sobre el manejo de su información. 
3.2.1.Derecho de Libertad Informativa o de Autodeterminación Informativa.- Derecho que si bien fuera introducido y elevado a rango constitucional por el Tribunal Constitucional Federal Alemán bajo el nomen iuris de "Informationelle Selbstbestim Mungsrecht", mediante sentencia dictada en fecha 15 de diciembre de 1983, en un proceso de inconstitucionalidad, actualmente albergaría más acertadamente el denominado derecho de autodeterminación informática.

Siendo la concepción que mejor se circunscribe a este derecho entenderlo como la libertad de la persona de informarse y verificar la información que edifica su identidad informática, a partir de la data existente sobre el mismo en archivos públicos o privados, en ejercicio de su poder de control sobre la calidad de lo registrado, así como de tener la posibilidad de corregir la información inexacta, complementar la insuficiente o cancelar la que no debe figurar en ellos, mediante el empleo de efectivos mecanismos legales previstos para dicho objeto.

Connotación de la cual se puede extraer que el contenido esencial del derecho de autodeterminación informativa tendría su expresión en los derechos de: a) Indagación (para conocer la existencia de registros con información personal), b) Información (para conocer en detalle el contenido de su información registrada, los fines de su registro y el potencial destinatario de la misma), c) Enmienda (para exigir la modificación, rectificación, o complementación de la información existente sobre si), d) Exclusión (para solicitar su cancelación, ocultamiento y eliminación de información sensible), y e) Reserva (para exigir que su información no sea entregada a terceros sin su consentimiento previo), los que frente a una amenaza o vulneración puedan ser atendidos veraz y oportunamente.

Esto es así, en correspondencia al derecho-obligación de autorregulación que contemporáneamente se entrega y exige al sujeto de derecho, puesto que de poco serviría tener mayor o menor cuidado con la información que se provee si la misma no va a poder ser sujeta a una correcta fiscalización y monitoreo por el titular de la información una vez ésta haya salido de su absoluto y estricto dominio privado. De lo que es factible afirmar que si bien es deber del individuo desplegar las acciones de control sobre la información que le concierne, no es menos cierto que es deber del Estado generar las condiciones mínimas necesarias para garantizar dicha custodia, ya que en la sociedad actual que enfrentamos resulta poco menos que imposible no observar la deliberada manipulación y circulación que se hace de la información personal que (por el motivo más irrelevante como la suscripción a una aplicación en el dispositivo 
móvil o la obtención de una tarjeta de crédito) se pudo proporcionar a un tercero y éste, cede muchas veces, sin autorización del titular.

\subsubsection{Derecho de Libertad Informática o de Autodeterminación} Informática.- Conforme se apuntaba, actualmente resulta sumamente complicado pretender sustraerse de escenarios que automáticamente registran toda información que llega a su poder, ya sean sitios web, navegadores, redes sociales, aplicativos móviles, entidades públicas y privadas de carácter financiero, educativo, cultural, medico, agencias de viaje, compras virtuales, y un largo etcétera de espacios con los que el hombre contemporáneo interactúa en su día a día para satisfacer sus aspiraciones y necesidades, en afán del libre desarrollo de su personalidad; espacios en los que el Estado no puede ni debe ser omnipresente, por lo que resulta natural poner en manos de los mismos titulares de derechos la custodia inmediata de los mismos, para lo cual, claro está, éstos deben contar con las condiciones mínimas que garanticen el ejercicio de libertades y los mecanismos de protección en caso que los mismos se vean amenazados o afectados.

Circunstancias de las que emerge el reciente Derecho a la Libertad Informática - término inicialmente acuñado por la doctrina italiana y desarrollado más tarde por la doctrina iberoamericana - que enmarca al derecho de la persona a la libre disposición de sus datos personales, familiares eíntimos que construyen su identidad virtual, en cuya virtud solo la misma como titular de la data pueda decidir autónomamente que, cuando, como, hasta donde y con quienes revelar aspectos relacionados a su personalidad. Ostentando por ello el derecho de ejercer control sobre dicha información, para cuyo objeto posee los derechos implícitos de: a) Autorización (para el registro, almacenamiento, tratamiento, utilización, distribución y publicación de su información) b) Fiscalización (de la autenticidad, estado, fines y nivel de propagación de su información), c) Rectificación (para corregir, modificar, ampliar o reducir la información obrante en los registros), d) Cancelación (respecto de una parte o toda la información registrada por haberse cumplido la finalidad de su obtención, por haberse utilizado para fines diferentes a su obtención, por haberse adulterado sin consentimiento el contenido de la información suministrada), y e) Oposición (para impedir la distribución, difusión y publicación de la información obrante), ya que cualquier forma de manipulación informativa diferente a los fines para el que se consintió su entrega o registro, afectaría directamente el derecho de la libertad de disposición informativa, esto es, de la libertad informática en sí misma. 
De ahí que resulta particularmente interesante, para el pleno ejercicio de este derecho, reforzar legislativamente la figura de la Entrega Consciente de Información, sus variantes y sus límites, ya que es a partir de ello que una persona pueda tener el control respecto a la información que entrega a terceros y sobre la cual cede, en cierta medida, un poder sobre su manejo. Para lo cual, desagregando las formas de la Entrega de Información - en tanto exteriorización de la voluntad y en cuanto instrumento de autorregulación (ambos como expresión del derecho a la libertad) - se observa los supuestos de: a) Consentimiento Informado, entendido como la expresión de voluntad libre, previa, expresa, informada e inequívoca de una persona para un fin determinado; b) Consentimiento Formal, constituido por la manifestación de voluntad plasmado bajo formalidades de Ley, para situaciones que por su propia naturaleza así lo exijan; y, c) Consentimiento Implícito o Constructivo, concebido como aquella voluntad expresada e inferida a través de la conducta del titular de derechos; frente a lo que cabe preguntarse si ¿todos los supuestos tienen las condiciones necesarias para entrar en la categoría de Entrega Consciente de la Información y ser tratados como tal?, de ser así, verificar si ello le brinda al titular de la data actuar su libertad con las garantías debidas sin afectar sus derechos.

En esa misma línea, también trasciende reparar en la necesidad de regular los alcances y límites del Tratamiento Invisible de Información, en la medida de lo posible, a fin de evitar la intromisión imperceptible en el área de la soberanía individual, puesto que, más allá de la entrega consciente de información que muchas veces la persona efectúa a los diversos bancos de datos, existe un plano donde el registro y procesamiento de su información - no necesariamente - se efectúa previo conocimiento y consentimiento del titular de la información, refiriéndonos por ello a la navegación en internet, en la quea través de interfaces, navegadores, buscadores, cookies, vínculos y enlaces automáticos se va registrando, procesando y muchas veces transmitiendo simultáneamente información del individuo, que en ocasiones desmesuradamente pasa del tratamiento de datos estrictamente necesarios y hasta justificados, tanto por razones de seguridad nacional como por fines comerciales, al tratamiento de información calificada como sensible, llegando con ello a afectar el contenido del derecho a la intimidad propiamente dicha y el derecho a la libertad informática.

\subsection{Dimensión Prospectiva: Derecho a la Extimidad}

Aunque pueda pensarse que el desarrollo tecnológico en materia de comunicaciones, haya tenido como uno de sus múltiples impactos en el hecho 
de que el ser humano sienta súbitamente la necesidad de exponerse y capturar la atención de sus congéneres, afirmarlo no le haría justicia a la naturaleza humana, puesto que mucho antes de los diversos instrumentos con los que se cuenta en la actualidad, el hombre ha sentido esa innata necesidad de afirmarse a través de los demás, de buscar su ser en el reconocimiento de terceros, y así lo afirmaría el psicoanalista francés Tisseron al señalar que: "(...) el deseo de exponerse es fundamental al ser humano y es anterior al de deseo de privacidad. Esta peculiaridad humana ya se manifiesta en los primeros meses de vida a partir del momento en que el bebé se descubre por medio de expresiones de la cara de su madre. Así la auto-presentación es un modo de mirar a sí, a través de los ojos de los demás a lo largo de la vida. En un sentido amplio, a través de las reacciones percibidas en el otro, obtener una confirmación de sí mismo."(Tisseron, 2001). Ahora que, si sería válido reconocerle a las TICs el incremento del deseo de visibilidad, al proyectar sus posibilidades de hacerlo más allá de su habitual circulo socio-afectivo a través de la exposición y hasta sobreexposición de parte de su vida privada en redes sociales.

Dicho ello, es factible postular al derecho a la extimidad como la posibilidad de insertarse libremente en el escenario digital - como expresión del derecho al libre desarrollo de la personalidad - a través del cual tener una ventana más de libertad para compartir revelaciones de algunos aspectos seleccionados de su esfera privada, con una determinada comunidad de personas en la que interactúa, en la que pueda emitir y recibir apreciaciones que tengan como limite el respeto por el contenido y alcances del derecho a la dignidad humana, en cuya virtud no sean condenados, infravalorados o discriminados ilegitima y arbitrariamente. Para lo cual se debiera acoger este derecho en un marco regulatorio y dotarlo de contenido que, bien podría tener expresión en los derechos de: a) Informar (para compartir contenidos en su espacio virtual), b) Convenir (para admitir y rechazar a otros individuos en su comunidad), y c) Excluir (para cancelar, ocultar y eliminar información y contenidos de dicha plataforma); por cuanto si bien, de entre todos los derechos previamente anotados, es éste el que tiene mayor incidencia y despliegue en la autorregulación, no por ello debiera ser un área exenta de protección constitucional, en aspectos muy estrictos.

\section{Protección en el Derecho Interno: Habeas data}

Acorde a lo anotado líneas arriba, el Derecho de la Intimidad alberga varias dimensiones, de las cuales a efecto de continuar la presente, únicamente interesa desarrollar los mecanismos de protección que el derecho nacional le brinda a su dimensión positiva, vale decir, al Derecho de la Protección de Datos Personales y los derechos en el contenidos, puesto que, conforme se hiciera mención el Derecho $a$ la Intimidad (en sentido estricto) cuenta con mecanismos de protección que no son objeto de análisis, y a su turno el emergente Derecho a la Extimidad aún no tiene cabida en nuestro ordenamiento jurídico interno. 
En tal sentido, a fin de garantizar el respeto al derecho de la protección de datos personales, en tanto manifestación del derecho a la libertad, “(...) frente al avance tecnológico y a la informática y su potencial invasión de la esfera privada, el principal cauce procesal para proteger la libertad de la persona es el denominado Hábeas Data, que cumple respecto de la libertad informática una función semejante a la que desempeña el hábeas corpus ante la libertad física (...) dos garantías procesales complementarias, que se ocupan de aspectos diferentes de la libertad: el primero, proteger principalmente aspectos internos de la libertad - identidad, intimidad -, en tanto que el segundo se ocupa de la dimensión física y externa."(Pérez, 1992, págs. 40-41).

Vértice a partir del cual atañe ingresar a observar el diseño que tiene el Habeas Data - reconocido por vez primera como garantía y mecanismo de protección específica en la Constitución del Brasil de 1988 - en el derecho interno, así, conforme a lo dispuesto por el inciso 3 del artículo 200 de la Constitución Política del Perú el Hábeas Data procede contra el hecho u omisión que vulnera o amenaza los derechos a que se refieren los incisos 5 y 6 de su artículo 2, los que estipulan que toda persona tiene derecho: "A solicitar sin expresión de causa la información que requiera y a recibirla de cualquier entidad pública, en el plazo legal, con el costo que suponga el pedido. Se exceptúan las informaciones que afectan la intimidad personal y las que expresamente se excluyan por ley o por razones de seguridad nacional. / El secreto bancario y la reserva tributaria pueden levantarse a pedido del Juez, del Fiscal de la Nación, o de una comisión investigadora del Congreso con arreglo a ley y siempre que se refieran al caso investigado.", y "A que los servicios informáticos, computarizados o no, públicos o privados, no suministren informaciones que afecten la intimidad personal y familiar", respectivamente. No obstante, el Código Procesal Constitucional, en su artículo 61, efectúa las precisiones siguientes: “(...). En consecuencia, toda persona puede acudir a dicho proceso para: 1) Acceder a información que obre en poder de cualquier entidad pública, ya se trate de la que generen, produzcan, procesen o posean, incluida la que obra en expedientes terminados o en trámite, estudios, dictámenes, opiniones, datos estadísticos, informes técnicos y cualquier otro documento que la administración pública tenga en su poder, cualquiera que sea la forma de expresión, ya sea gráfica, sonora, visual, electromagnética o que obre en cualquier otro tipo de soporte material. 2) Conocer, actualizar, incluir y suprimir o rectificar la información o datos referidos a su persona que se encuentren almacenados o registrados en forma manual, mecánica o informática, en archivos, bancos de datos o registros de entidades públicas o de instituciones privadas que brinden servicio o acceso a terceros. Asimismo, a hacer suprimir o impedir que se suministren datos o informaciones de carácter sensible o privado que afecten derechos constitucionales.", prescripciones que posteriormente fueron complementadas y enriquecidas a través del 
desarrollo jurisprudencial elaborado por nuestro Tribunal Constitucional, a partir de todo lo que es posible apreciar los siguientes aspectos:

1. La Constitución peruana configura al Habeas Data como una acción con objetivos múltiples, al identificar de manera diferenciada por un lado el derecho de acceso a la información y por otro el derecho a la protección de los datos, al tiempo de proyectarlo como un mecanismo de protección de datos de carácter personal (Habeas Data Propio) y de protección del derecho al acceso a la información pública (Habeas Data Impropio / Impuro), habiendo sido por ello la primera Constitución en incorporar y aun ser actualmente una de las pocas que tiene incorporada el Habeas Data Impropio, respecto al cual en esta ocasión no se hará mayor mención.

2. En el Perú, la protección del derecho a la intimidad, es delegada al proceso de Amparo, a diferencia de algunos países iberoamericanos.

3. Del marco normativo es factible advertir que el Habeas Data se activa frente a diferentes niveles de afectación, como son: a) Amenaza inminente, b) Afectación vigente, y c) Afectación concretada, frente a las que se ofrece la respuesta más apropiada a cada circunstancia.

4. De la doctrina jurisprudencial desarrollada a la fecha ${ }^{3}$ es posible ver que en relación a la protección del Derecho de la Protección de Datos Personales - en toda su dimensión - el Tribunal Constitucional ha señalado, con fines pedagógicos, tipos específicos de Habeas Data "Puro" frente a las diferentes formas de afectación de las que puede ser pasible el derecho en estudio, los que, en resumidas líneas, serían: a) Hábeas Data de Cognición: Para el conocimiento y supervisión de la utilización informativa de datos almacenados; a.1) Hábeas Data Informativo: Para acceder al contenido de la información que se almacena en un banco de datos; a.2) Hábeas Data Inquisitivo: Para exigir la identidad de quien proporcionó un dato; a.3) Hábeas Data Teleológico: Para el conocimiento del objeto y finalidad del registro de un dato personal; a.4) Hábeas Data de Ubicación: Para ser informado sobre la ubicación y/o ubicaciones de datos personales de su titular; b) Hábeas Data Manipulador: Para conseguir la modificación de la información personal registrada; b.1) Hábeas Data Aditivo: Para agregar, actualizar, aclarar e incorporar cierta data omitida que perjudica a su titular; b.2) Hábeas Data Correctivo: Para modificar los datos imprecisos y cambiar o borrar los falsos; b.3) Hábeas Data Supresorio: Para eliminar información sensible, datos que afectan la intimidad personal, familiar o cualquier otro derecho fundamental, e información que no se adecua a la finalidad para la cual ha sido registrada; b.4) Hábeas Data Confidencial: Para impedir el acceso 
a información reservada a personas no autorizadas; b.5) Hábeas Data Desvinculador: Para impedir a terceros del conocimiento de la identidad de personas cuyos registros se hayan efectuados en función de aspectos generales; b.6) Hábeas Data Cifrador: Para solicitar el almacenamiento de ciertos datos de manera codificada al que sólo pueda acceder el autorizado de hacerlo; b.7) Hábeas Data Cautelar: Para evitar la manipulación o publicación del dato en el marco de un proceso, a fin de asegurar la eficacia del derecho que se busca proteger; b.8) Hábeas Data Garantista: Para controlar el manejo, garantía de confidencialidad y condiciones mínimas de seguridad de los datos y su utilización acode con la finalidad de su registro; y b.9) Hábeas Data Interpretativo: Para impugnar las valoraciones de quien analiza la información personal almacenada. Todos ellos a fin de evitar, de algún modo, cualquier tipo de injerencia ilegitima de terceros en el libre manejo de éste derecho por su titular, ya sea por el uso indebido o una indebida intromisión en el registro, almacenamiento, recolección, tratamiento, distribución, transmisión, análisis, valoración, adulteración, seguimiento, interceptación, destrucción, publicación o difusión de información de carácter personal sin la previa autorización de su titular.

5. Que, el proceso constitucional de Habeas Data, pese a no ser señalarlo expresamente tiene: una finalidad inmediata - que, independientemente de garantizar la tutela al derecho de la protección de datos personales - busca proteger los derechos a la intimidad, a la confidencialidad (expresado con mayor resonancia en la inviolabilidad del secreto a las comunicaciones y reserva tributaria) y al libre consentimiento (expresión del libe desarrollo de la personalidad); y una finalidad mediata, por la que además busca custodiar a la persona humana de otras agresiones como la actuación discriminatoria, suplantación de identidad, conducta extorsiva, defraudación financiera, acoso y hostigamiento, calumnias y difamaciones, y formas de abuso de poder estatal como la represión de grupos, por cuanto se entiende que mediante el poder informativo es posible hacer ello y más.

De otro lado, corresponde ahora precisar que el Habeas Data no es a la fecha el único mecanismo que el estado peruano ha previsto para la protección de data de carácter personal, puesto que en el año 2011 promulgaría la Ley № 29733, Ley de Protección de Datos Personales, y posteriormente en 2013 su reglamento, aprobado mediante D.S. № 003-2013-JUS, en cuya virtud se incorporarían y habilitarían procedimientos en la vía administrativa, y el proceso contencioso administrativo en la vía judicial, sin que ello represente una vía previa al proceso constitucional en mención. No obstante, a fin de continuar mejorando dicho desarrollo, cabe puntualizar a modo de critica 
que, pese a los esfuerzos, dichas normas no proyectan aun precisiones respecto a: a) Situaciones de interceptación ilegitima y tratamiento invisible de datos; b) Todos los sujetos responsables de las potenciales agresiones, ya que únicamente se refieren en ellas a los titulares de la información, a los titulares y encargados de los bancos de datos y a los responsables delegados para su tratamiento, mas no incluyendo así a los proveedores de redes, a los proveedores de servicios de comunicaciones y a los titulares de servidores; y c) Sanciones suficientemente adecuadas para disuadir la vulneración de derechos. Así como algunas otras cuestiones que por su propia naturaleza no le es posible controlar.

\section{Protección en el Derecho Internacional:}

Conforme se ha podido ya observar, debido a la propia naturaleza de sus alcances y limites jurisdiccionales, acciones como implementar un adecuado mecanismo de control e imponer las medidas sancionatorias proporcionales frente a las posibles vulneraciones al derecho de la protección de datos personales, se torna relativamente complicado para el derecho interno, pero no solo para el caso del Perú sino para el derecho interno de muchos países en general, por lo que a fin lograr sus fines dicha materia bien podría ser pasible de una regulación detallada en el derecho internacional, en tanto espacio normativo multidimensional, en cuyo plano si podría optimizarse la protección de ciertas situaciones que puedan resultar de complejo conocimiento para el derecho interno, al tratarse de un derecho que permanentemente converge en un espacio abierto donde el irrestricto flujo de data permeabiliza las fronteras del tiempo y distancias.

No obstante, previamente a continuar con dicha osada y aun tenue propuesta, cabe recapitular el sendero ya andado por el derecho internacional en dicha materia, ya que recordemos que es a partir de su influencia que, se produce tanto para el sistema jurídico continental como para el sistema jurídico iberoamericano, el proceso de reconocimiento constitucional del derecho en mención con mayor dinamismo, así veamos:

- Una de las primeras aproximaciones respecto a la introducción del derecho de la intimidad en un instrumento jurídico internacional vendría dado en el tenor del artículo 5 de la Declaración Americana de Derechos y Deberes del Hombre de mayo de 1948.

- Pocos meses después, se puede observar semejante reconocimiento en el artículo 12 de la Declaración Universal de Derechos Humanos de diciembre de 1948.

- Tiempo después llegaría, ya en relación a la normativa europea, el Convenio Europeo para la Protección de los Derechos Humanos y de las Libertades Fundamentales de 1950, que en su artículo 8 enunciara 
la protección para el derecho a la vida privada y a la reserva a la correspondencia.

- Tras lo cual se continuaría con la adopción de preceptos en similar sentido, tanto en el artículo 17 del Pacto Internacional de Derechos Civiles y Políticos de 1966, como en el artículo 11 de la Convención Americana sobre Derechos Humanos de 1969.

- No obstante, ya dos años antes del último instrumento pre señalado, en 1967 en Europa se detectaba la amenaza para las libertades del individuo en relación a su vida privada, por cuyo motivo se constituiría una comisión consultiva cuyo trabajo concluiría en 1968, con la aprobación de la Resolución $N^{\circ} 65 / 509 / C E$ por la Asamblea Consultiva del Consejo de Europa, adoptada en la XIX sesión ordinaria sobre Derechos Humanos y los logros científicos y técnicos; siendo éste el vértice que le diera un rumbo ya más acentuado al derecho de la protección de datos personales como tal.

- Ese mismo año, en 1968 con ocasión de la Conferencia Internacional de Derechos Humanos en Teherán, en conmemoración del XX aniversario de la Declaración Universal de Derechos Humanos, se iniciaban debates en relación a la incidencia de la informática en los derechos individuales y como se enfrentaría su protección.

- No sería, sin embargo, sino hasta enero de 1981 en que viera la luz el Convenio 108 adoptado por el Consejo de Europa, que tuvo lugar el primer instrumento internacional que pretendiera trascender las legislaciones internas, con miras a disponer una normativa comunitaria armonizada respecto a la protección de datos personales frente al tratamiento automatizado de los mismos; y que aun a la fecha es de los pocos actos jurídicamente vinculantes en el ámbito internacional.

- Posteriormente en el marco de la Asamblea General de la ONU, desarrollada en diciembre de 1990, se adoptaría la Resolución 45/95, en cuya virtud se establecieran los Principios Rectores para la Reglamentación de los Ficheros Computarizados de Datos Personales, sentando con ello las bases mínimas sobre las que cada legislación nacional debiera reglamentar sobre la protección de los datos personales.

- Luego tendrían lugar las Directivas: $N^{\circ} 1995 / 46 / C E$, de octubre de 1995, relativa a la protección de las personas físicas, el tratamiento de datos personales y la libre circulación de los mismos; $N^{\circ}$ $1997 / 66 / C E$, de diciembre de 1997, relativa al tratamiento de datos personales y a la protección de la intimidad en el sector de las 
telecomunicaciones; $N^{\circ} 2000 / 31 / C E$, de junio del 2000, relativa a determinados aspectos jurídicos de los servicios de la sociedad de la información, y en particular el comercio electrónico en el mercado interior; $N^{\circ} 2002 / 58 / C E$, de julio de 2002, relativa al tratamiento de los datos personales y a la protección de la intimidad en el sector de las comunicaciones; $N^{\circ} 2006 / 24 / C E$, de febrero de 2006, relativa a la conservación de datos generados o tratados en relación con la prestación de servicios de comunicaciones electrónicas de acceso público o de redes públicas de comunicaciones; $N^{\circ} 2009 / 136 / C E$, de noviembre de 2009, que modifica las Directivas 2002/22/CE y 2002/58/CE.

- Otro instrumento importante a resaltar en este apartado resulta ser la Carta de los Derechos Fundamentales de la Unión Europea, de diciembre del 2000, puesto que en ella se da un importante viraje al concebir al derecho de protección de datos personales como un derecho fundamental, autónomo e independiente, al regularlo en un articulado diferente al del derecho a la vida privada y familiar.

- Complementariamente también en diciembre del 2000 se aprobaría el Reglamento № 45/2001/CE, relativo a la protección del tratamiento de datos personales por las instituciones y los organismos comunitarios y a la libre circulación de estos datos, en la cual es importante destacar: a) El Refuerzo de la prohibición de tratamiento de los datos sensibles; b) La creación de una autoridad de control independiente para el sistema comunitario; c) El reconocimiento de los derechos a la información, de acceso, de rectificación, de bloqueo, de supresión, derecho de oposición y de comunicación; d) La fijación de los criterios para la licitud del tratamiento de datos; e) El establecimiento de reglas para la transmisión de datos personales según los destinatarios, sean o no distintos de las instituciones y los organismos comunitarios; y f) El intento de fijar obligaciones de los responsables del tratamiento de datos dentro de las instituciones y los organismos comunitarios.

- El que, fuera derogado con la entrada en vigencia del Reglamento $N^{\circ}$ 2016/679/UE, de abril de 2016, que trae consigo significativos aportes como: a) Extensión del ámbito de aplicación territorial, en cuanto a responsabilidades aun para aquellos que no tengan ninguna presencia física en el territorio de la UE, siempre que se involucre de algún modo a un residente de la UE; b) Refuerza el consentimiento informado, exigiendo para su configuración una acción positiva del titular de derechos, descartándose todo tipo de consentimiento tácito, poniendo aun mayor cuidado para el caso de menores; c) Establece reconocimiento al derecho al olvido y al 
de portabilidad de datos; d) Refuerzo del deber de información al interesado en el momento del recojo de sus datos o inmediatamente después (de haber sido obtenida de otra fuente), sobre todo lo relativo a sus fines y demás; e) Obligación del responsable del tratamiento de notificar oportunamente de los fallos de seguridad en el sistema, tanto a la autoridad de control, como a los interesados; f) Precisión de obligaciones y responsabilidades a las empresas que realicen tratamientos y a las delegadas de estas; g) La fijación de competencia territorial de las autoridades de control de protección de datos; h) Establecimiento de medidas de seguridad mínimas y orientativas para el tratamiento de satos; y i) Modificación en las cuantías de sanciones con rangos bastante notorios.

Llegado a este punto cabe hacer notar la evidente posición encontrada que existe entre el sistema norteamericano con el europeo, ya que mientras este último tiende a tener una visión más proteccionista, el primero prefiere la autorregulación y la adopción de códigos de conducta de las compañías. Por cuyo hecho, a fin de evitar complicaciones comerciales, en el intento de acercar posturas, el Departamento de Comercio estadounidense conjuntamente con la Comisión Europea suscriben el Acuerdo de Puerto seguro, en cuya virtud las empresas norteamericanas que se adhiriesen a los principios europeos de protección de datos podían transferir datos de sus clientes de la UE a los de USA. Acuerdo que, sin embargo, fuera dejado sin efecto mediante sentencia emitida en fecha 6 de octubre de 2015, por el Tribunal de Justicia de la Unión Europea.

No obstante ello, a fin de superar dicha brecha y reanudar sus relaciones comerciales en las que resulta necesario el tráfico de data, la Comisión Europea y el Gobierno de los Estados Unidos, en fecha el 12 de julio de 2016, arribaron a un acuerdo político estableciendo un nuevo marco normativo para los intercambios transatlánticos de datos personales con fines comerciales denominado Escudo de Privacidad UE-EE.UU, que reflejaría los requisitos establecidos en la referida sentencia.

\section{Conclusiones}

Superada la revisión de avances producidos tanto a nivel europeo como a nivel norteamericano en materia de protección de datos personales, corresponde verificar ahora, si dichos avances se han producido también de manera homogénea en Latinoamérica. Cuestión frente a la que, sin mayor preámbulo, se puede señalar no, la producción normativa en este continente evidentemente no se ha generado del mismo modo, ya que de este lado del globo terráqueo el avance ha sido más heterogéneo, habiendo tenido mayor repercusión en el derecho interno de los países de forma aislada e independiente. 
Situación que al versar sobre una materia de irradiación tan singular, lógicamente genera complicaciones para abordarlo de manera óptima, por lo que reproduciendo el planteamiento formulado a inicios del apartado precedente, bien podría proponerse, en el seno de un organismo internacional adecuado, la elaboración de un instrumento jurídico uniforme sobre la protección del derecho objeto de análisis, que coadyuve a superar los principales obstáculos que puedan acometerlo, tales como: a) El ámbito de aplicación, en el sentido que puede resultar sumamente complejo exigir el cumplimiento de ciertas condiciones a empresas que muchas veces ni siquiera cuentan con una sede local en territorio nacional; b) La competencia territorial, debido a la dificultad que pueda representar para un solo Estado definir los alcances de su proyección normativa y determinar el ámbito de su actuación frente a una agresión que implique múltiples espacios como el domicilio del titular afectado, el domicilio del responsable del tratamiento de la información, y el lugar de producción del evento violatorio, que no siempre coinciden en ser los mismos; c) La determinación de responsables, debido a que normalmente, como en el caso de Perú, las legislaciones internas fijan su atención en los bancos de datos, olvidando que no son los únicos que intervienen en el flujo informático; d) La temporalidad para intervención, ello en el sentido que no siempre la persona afectada tomará oportuno conocimiento y en consecuencia podrá denunciar inmediatamente una vulneración, para lo que debería fijarse las pautas; e) La indeterminación de los niveles de impacto, ello por el mismo hecho que puede resultar complejo determinar el espacio de producción de una afectación, ya sea que se dio a nivel de su arquitectura, tecnología, productos complementarios o servicios externos; y f) La actividad probatoria, ello principalmente en cuanto a la determinación de responsables en espacios múltiples.

Para lo cual, claro, los diferentes países tendrían que analizar y ponderar mínimamente la relación articulada entre: a) Derechos humanos, b) Integración económica, c) Intereses globales, y d) Soberanía nacional, necesarios todos ellos para un adecuado escenario comunitario de cooperación y desarrollo conjunto, propio de una sociedad globalizada con espacios comunes de interés.

Concierto tras el que se pudiese lograr una regulación conjunta más acuciosa o en su defecto parámetros estándares para las legislaciones internas, con especial incidencia en el desarrollo de: a) Derechos de titulares, b) Obligaciones de agentes involucrados (incluyendo al titular de derechos), c) Definición de responsables (con alcance a los proveedores de redes, proveedores de servicios de comunicaciones, bancos de datos, responsables de tratamiento informático y titulares de servidores), d) Mecanismos idóneos de control (antes, durante y posterior a los procesos de tratamientos de data), e) Órgano supervisor (con alcances suficientes para un efectivo control), y f) Sanciones adecuadas (a fin de lograr un compromiso ético por parte de 
quienes intervienen en los diferentes procesos para el tratamiento de datos). No obstante, en tanto se construye un escenario optimo, corresponde a los titulares de derechos adoptar una conducta más diligente en el manejo de su información.

\section{Referencias}

Arce Janariz, Alberto. (1996). «El Derecho a la Intimidad», de Samuel D. Warren y Louis D. Brandéis. Revista Española de Derecho Constitucional, $\mathrm{N}^{\circ} 47$.

Delpiazzo Rodríguez, Carlos Enrique. (2002). Protección de los Datos Personales en Tiempos de Internet: El Nuevo Rostro del Derecho a la Intimidad. Revista de Derecho de la UCU, $\mathrm{N}^{\circ} \mathrm{III}$.

Delpiazzo Rodríguez, Carlos Enrique. (2007). El Principio de Seguridad Jurídica en el Mundo Virtual. Revista de Derecho de la UM, N 11.

Ferrajoli, Luigi. (2006). Sobre los Derechos Fundamentales. Revista Cuestiones Constitucionales de la UNAM, $\mathrm{N}^{\circ} 15$.

García Fernández, Dora. (2010). El Derecho a la Intimidad y el Fenómeno de la Extimidad. Revista Dereito de la USC, Vol. 19, № 02.

Lucena Cid, Isabel Victoria. (2012). La Protección de la Intimidad en la Era Tecnológica: Hacia una Reconceptualización. Revista Internacional de Pensamiento Político, Vol. 7.

Palacios González, María Dolores. (2012). El poder de Autodeterminación de los Datos Personales en Internet. Revista de Internet, Derecho y Política de la UOC, № 14.

Pérez Luño, Antonio Enrique. (1986). La Defensa del Ciudadano y la Protección de Datos. Revista Vasca de Administración Pública, № 14.

Pérez Luño, Antonio Enrique. (1992). Intimidad y Protección de Datos Personales: Del Hábeas Corpus al Hábeas Data. Editorial Tecnos,

Puccinelli Parucci, Oscar Raúl. (2004). Evolución Histórica y Análisis de las Diversas Especies, Subespecies, Tipos y Subtipos de Habeas Data en América Latina: Un Intento Clasificador con Fines Didácticos. Revista Vniversitas de la PUJ, Vol. 53, ํำ 107.

Saldaña Díaz, María Nieves. (2011). El Derecho a la Privacidad en los Estados Unidos: Aproximación Diacrónica a los Intereses Constitucionales en juego. Revista Teoría y Realaidad Constitucional de la UNED, $\mathrm{N}^{\circ} 28$.

Saldaña Díaz, María Nieves. (2012). «The Right to Privacy» La Génesis de la Protección de la Privacidad en el Sistema Constitucional Norteamericano: El centenario legado de Warren y Brandeis. Revista de Derecho Político de la UNED, N 85.

Tisseron, Serge. (2001). La Intimidad Sobreexpuesta. Editorial Ramsay.

\section{Notas al final}

1 Maestrante en Derecho Procesal por la Universidad Nacional Mayor de San Marcos (UNMSM) Email: speraltaorosco@gmail.com

2 Neologismo atribuido al psiquiatra y psicoanalista francés Jacques-Marie Émile Lacan.

3 Sentencia de fecha 21 de diciembre del 2007, emitida en el Exp. № 06164-2007-HD/TC. 